\title{
METHODOLOGY FOR THE IMPLEMENTATION OF KNOWLEDGE MANAGEMENT
}

\author{
SYSTEMS \\ Ricardo Chalmeta $^{\mathrm{a}}$, Reyes Grangel ${ }^{\mathrm{a}}$ \\ a Grupo de Investigación en Integración y Re-Ingeniería de Sistemas (IRIS). \\ Universitat Jaume I. 12071 Castelló. Spain. \\ Tel: + $34964728329 ;$ Fax: + 34964728435 \\ \{rchalmet, grangel\}@uji.es
}

\begin{abstract}
Managing knowledge means managing the processes of creation, development, distribution and utilisation of knowledge in order to improve organisational performance and increase competitive capacity. However, serious difficulties arise when attempts are made to implement knowledge management in enterprises. One of the reasons behind this situation is the lack of suitable methodologies for guiding the process of development and implementation of a Knowledge Management System, which is a computer system that allows the processes of creating, collecting, organising, accessing and using knowledge to be automated as far as possible.

In this paper we propose a methodology for directing the process of developing and implementing a Knowledge Management System in any type of organisation. The methodology is organised in phases and outlines the activities to be performed, the techniques and supporting tools to be used, and the expected results for each phase. In addition, we show how the proposed methodology can be applied to the particular case of an enterprise.
\end{abstract}

Keywords: Methodology, Knowledge Management, Knowledge Management Systems, Enterprise, Information Systems 


\section{INTRODUCTION}

One of the novel ways for improving competitiveness and productivity in organisations is the implementation of Knowledge Management (KM), understood as meaning the capacity to create, collect, organise, access and use knowledge. This situation has arisen because:

- Company decisions and actions require a far greater amount of information and knowledge due to the more global and complex environment businesses currently have to operate in.

- There is an increased demand for greater knowledge intensity in products, processes and services. By applying knowledge to products and services, their value increases.

- Knowledge management stresses the importance of intangible assets and enables them to be used to advantage.

- Information and Communication Technologies open up numerous possibilities to improve knowledge management both within and among enterprises.

A key factor for achieving correct knowledge management in an organisation is the development and implementation of a Knowledge Management System (KMS), that is to say, a technological information system that supports knowledge management and allows knowledge to be created, codified, stored and distributed within the organisation automatically (Day, 2001).

Running a KMS development and implementation project in an organisation is an extremely complex process that involves different technological, human and organisational aspects. To ensure the project is successfully implemented, while at the same time reducing the level of complexity, it is necessary to follow a methodology that acts as a guide throughout the analysis, development and implementation of the KMS.

The methodologies that at first sight appear to be the most appropriate for KMS development and implementation are the methodologies that are oriented towards Information Systems Development, because a KMS is a kind of information system. 
Earlier studies have proposed various Information Systems Development methodologies (ISDM), which provide a consistent set of procedures to be followed (as well as tools, techniques and documentation that can be used) to make the process of managing and developing information systems more efficient and effective (Yadav et al., 2001). In addition, an ISDM implies a time-dependent sequence of action stages (Walters et al., 1994).

A wide range of such frameworks have been developed over the years. In this regard, in 1994 Jayaratna (1994) estimated that there were more than 1000 available for use. In Avison and Fitzgerald (2006) there is a good compilation and comparative analysis of the most important ones.

Each of these ISDM has its own acknowledged strengths and weaknesses. However, one ISDM is not necessarily suitable for use in all projects. Each methodology is best suited to a specific type of project due to their different technical, organisational, project and team considerations (Meso et al., 2006).

From our experience in developing KMS in real-world situations and in accordance with other authors like Viswanathan et al. (2005), who highlight the common weaknesses found in KMS development methodologies in practice, we can state that one of the chief reasons for the large number of failures in implementing a KMS is the lack of an ISDM which is specifically oriented towards the development of a KMS that reduces the complexity of the process. For example, when the currently existing ISDM are applied to the development of a KMS, at some stage it becomes necessary to specify the requirements the future KMS should meet. These ISDM do not, however, help users to identify them in a practical way. It would therefore be very useful for the users who have to define these requirements (which in this case is knowledge) to have a series of templates that include examples of typical items of knowledge that an organisation like theirs will be interested in managing. Thus, the process of specifying the requirements could be carried out more quickly and thoroughly. Another example is that, although existing methodologies make use of modelling languages to create a model of the computer system, they do not employ specific languages with profiles that are expressly oriented towards modelling knowledge. Such profiles would allow the knowledge map to be generated in a simple manner that is at the same time both graphic and intuitive. 
Consequently, there are a number of problems concerning the methodologies for developing KMS that remain unsolved and hence there is still room for significant improvement as regards both their theoretical aspects and their practical applicability (McInerney \& Day, 2002).

To help solve this problem, in this paper we propose a methodology that is structured in several different phases and can be used to guide projects intended to develop and implement knowledge management systems in an enterprise. The methodology makes it possible to: (1) gather, identify and separate knowledge from information; (2) store knowledge using a common language; and (3) make this knowledge widely available to whoever may need it. To collect data and test the operative capacity of the methodology, our work was carried out in collaboration with a large textile company.

The paper is organised as follows: the next section presents a review of what knowledge, knowledge management and knowledge management systems are and how they are related to the use and dissemination of knowledge within an organisation. In addition, the current situation as regards the development and implementation of knowledge management systems is analysed in order to determine the main reasons why they fail. Section three outlines the methodology proposed here for helping to develop and implement a KMS in any type of organisation. The methodology is organised in phases and outlines the activities to be performed, the techniques and the supporting tools to be used and the expected results for each phase. Section four shows an example of how this methodology could be applied in an enterprise. Finally, section five presents a case example, and section six offers the conclusions from the work.

\section{LITERATURE REVIEW}

There is no universally accepted definition of exactly what knowledge is. Some authors define it, for example, as the information individuals possess in their minds (Drestke, 1981). This definition is argued by saying that data (raw numbers and facts) exist within an organisation. After processing these data they 
are converted into information and, once it is actively possessed by an individual, this information in turn becomes knowledge. There are also other approaches to defining knowledge that are more independent of the information technologies. One of the most frequently cited is the approach proposed by Nonaka and Takeuchi (1995), who define knowledge as the justified belief that increases the capacity of an entity to take effective action. Following this line of reasoning, knowledge can be seen from five different perspectives (Alavi \& Leidner, 2001): (1) as a state of mind, (2) as an object, (3) as a process, (4) as a condition for accessing information, or (5) as a capability. Taking this context and our own empirical observations as our starting point, we define knowledge as the awareness that enables us to possess the skill or the capacity required in a particular situation (1) to deal with and resolve complex issues in an efficient and creative manner, and (2) to take advantage of opportunities by making the most appropriate decisions.

The process of converting the knowledge gained from the sources available to an organisation and then connecting people with that knowledge is one of the definitions provided to explain knowledge management (O'Leary et al., 1997; O’Leary, 1998; Myers, 1996). Therefore, the aim of knowledge management is to create, collect, store, access, transfer and reuse knowledge (Devedzic, 1999).

Knowledge management has been used in different kinds of organisations in order to boost profits, to become competitively innovative, or simply to survive (Abdullah et al., 2002). Different examples of its application are well described in a large number of papers. KM is used, for example, to create or assemble productive resources, including research, manufacturing, design, business, learning and training (Liao, 2003).

However, there are different problems that hamper its application, some of the most important being (Snowden, 2002):

- The complexity of the concept.

- The fact that its introduction requires specific organisational culture and practices, human resource policies, marketing and change management. 
- The intangibleness of its benefits: many business people find it difficult to associate investment in knowledge management with improvements in company results.

- The fact that it needs to be supported by the information and communication technologies.

Several different theories have been put forward to get to grips with the first three problems associated with knowledge management cited in the previous paragraph. Such proposals include the cognitive (Chiu et al., 2006), motivational (King \& Marks, 2006; Hall, 2003), economic (Ke \& Wei, 2005; Eliasson, 2005) or organisational theories (Gray \& Meister, 2006; Revilla et al., 2005). These theories have been used to deal with the formal aspects and essentially attempt to explain the concept of knowledge, its typology and the actions to be carried out in order to favour its development and management.

As far as the fourth problem is concerned, the generally accepted solution is to develop a Knowledge Management System, that is to say, a specialised system supported by information and communication technologies that interacts with the organisation's computer systems to make the processes of creating, collecting, organising, accessing and using knowledge as automatic as possible (Abdullah et al., 2002).

According to Ernst and Young (2001) organisations are basically putting into practice five types of projects related with KMS implementation: creation of Intranets and corporate portals; data warehouses or knowledge repositories (Inmon, 1996); implementation of decision support tools; implementation of groupware; and creation of document management systems (Lindvall, 2003).

Thus, the architecture of information systems in enterprises that wish to implement a Knowledge Management System should provide a set of tools for supporting the smart integration of all enterprise computer components.

However, the development and implementation of KMS that embrace the whole organisation, including knowledge resulting from its relations with other institutions that it collaborates with and which also incorporate the management of tacit knowledge, is a more complex affair that has still not been 
satisfactorily resolved (Heinrichs et al., 2005). In this regard, Schutt (2003) describes the evolution that the different generations of knowledge management systems have undergone and explains why they did not live up to the expectations they had raised. One of the main reasons, as confirmed by Shin et al. (2001), is the lack of a methodology to guide the KMS development and implementation project.

\section{KM-IRIS METHODOLOGY}

In order to successfully carry out a KMS development and implementation project, while at the same time reducing the degree of complexity, it would be a great aid to be able to use a stage-based methodology that defines the whole creative process in each phase. This would involve defining, among other things, the tasks to be performed, the techniques to be used, the modelling languages for representing the knowledge and the technological infrastructure that allows knowledge to be stored, processed and distributed, depending on the roles that have been defined.

With a view to solving this problem of a lack of such knowledge management methodologies, since 2003 the IRIS Group at the Universitat Jaume I in Castelló (Spain) has been working on a project entitled "Methodology for Knowledge Management". The objective was to develop and validate a useful, practical methodology that can be used to guide the process of developing and implementing a system for gathering, managing, applying and transferring the knowledge that is generated both inside an enterprise and in the relations it has with the different organisations it works with. At the same time it must also ensure the quality, security and authenticity of the knowledge supplied.

First of all, the methodology, called KM-IRIS, was defined on a general level so that it could be used as a guide to manage knowledge in any kind of organisation that wished to do so. It was later applied to a large textile enterprise in order to (1) validate and document the benefits and lessons learned in the form of a properly understandable case study, and (2) improve the initial results by applying the conclusions extracted from those findings to them. 
The general methodology is divided into five phases:

1. Analysis and Identification of the Target Knowledge.

2. Extraction of the Target Knowledge.

3. Classification and Representation.

4. Processing and Storage.

5. Utilisation and Continuous Improvement.

We will now describe each of the phases that go to make up the methodology in more detail, that is, the activities involved in each step, the techniques and tools that can be used to aid the process, and the main results that are to be expected (see Figure 1).

\section{PHASE I. Identification}

One of the aspects that usually generates most confusion in knowledge management is the difference between knowledge and information. This uncertainty is increased by the fact that knowledge management relies on information technologies for support instead of a set of specific technologies that could be called 'knowledge technologies'. If information and knowledge are not the same, then there seems to be something strange about the fact that knowledge can be handled using technologies that were designed for processing information.

Figure 2 attempts to unravel this paradox. As we see it, knowledge and information are different. The individual who possesses knowledge (i.e. the awareness that he or she has acquired through their training, common sense, experience, and so on) (McInerney, 2002) needs to analyse and assess information so that, in a given situation, they can make the right decisions or carry out the activities that have been proposed. In this context, the goal of the knowledge management system is to identify existing knowledge and extract, collect and codify it as information so that it can be stored and distributed using a computer system. Thus, the knowledge management system transforms the organisation's knowledge into information that will later be utilised by individuals to make better decisions or to better perform their tasks and duties. The quantity and quality of information that is 
used by the individuals in the organisation to make decisions based on their knowledge therefore increases, since now it is not only produced by processing data but also comes from already existing knowledge. Moreover, the KMS helps to generate new knowledge because having more information available means that, when faced with the same situation, individuals are more likely to make a different kind of decision or to solve problems in a more efficient way, which in turn is a source of feedback for the system.

In this context, we call the organisation's knowledge that will be extracted, processed and codified in a KMS (thereby converting it into information) target knowledge (Grangel et al., 2006).

Therefore, the aim of this first phase of the methodology is to identify the knowledge that is going to be managed by the system, that is to say, the target knowledge. In order to identify this knowledge we need to use a pragmatic vision by directing the search towards the knowledge that is useful to the organisation and will provide an added value when utilised. To make it easier to identify in an organised fashion, it is better to begin by defining blocks of knowledge, which are understood as being any elements belonging to the organisation or to its surroundings that contain a particular type of knowledge. These conceptual blocks of knowledge are different for each type of organisation, and may even differ within the same kind of organisation, since such blocks can only be defined by taking into account the strategic objectives of the organisation and its core activities.

Once the elements of the organisation we want to know about (conceptual blocks of knowledge) have been defined, we have to identify what target knowledge will need to be extracted, represented and utilised in each of these conceptual blocks.

Finally, after identifying the knowledge in each block we must provide a detailed description of the knowledge that has been defined as target knowledge and, depending on the volume, perhaps build up an ontological classification so that it can be represented, processed and utilised at a later stage.

Valuable aids to carry out this phase include resources such as templates, questionnaires and reference models that help organisations of the same type or sector to define their conceptual blocks of knowledge, as well as to identify, describe and classify the target knowledge. 


\section{PHASE II. Extraction}

The aim of this phase is to define suitable mechanisms with which to obtain the target knowledge that was identified in the previous step. To achieve this, first we must define the input variables that we are going to have to use in order to obtain the target knowledge. These input variables may be data or documents that are in the organisation's information system, that is to say, in sources of explicit knowledge, in which case they will be called explicit input variables. On the other hand, they might consist of information or knowledge held by people related to the organisation, that is, they lie in sources of tacit knowledge, in which case they will be labelled tacit input variables. However, in our opinion, it will not be possible to extract and codify all tacit variables. In theory, only technical tacit variables (which refer to know-how and skills that apply to a specific context) can be documented (Day, 2005). Since it is difficult to record, process and operate with cognitive tacit variables such as beliefs or personal values using computers, they are not taken into account within the management information system that is to be developed.

Another source of variables will be the actual knowledge management system itself, since one or several input variables could be target knowledge generated by the knowledge management system that has been implemented in the organisation, and which can be used to create new knowledge. So it must therefore be capable of providing itself with feedback.

Once the variables have been defined we must identify the sources of knowledge, which are understood to mean any components within or outside an organisation that supply those variables.

Finally, we have to define the procedure that is going to be used to extract the variables from the sources and also the method of calculation - the algorithm - that allows target knowledge to be obtained by combining the input variables. These procedures will vary according to the conceptual block of knowledge that is being dealt with and the input variables that have been defined (see Figure 3).

At this point it is important to draw attention to the difference between what we call conceptual blocks of knowledge and sources of knowledge. Whereas the former refers to an ontological grouping of 
knowledge, the latter is concerned with the starting point that will be used to extract it. For example, in the first phase of the KM-IRIS methodology an organisation might identify the conceptual block of knowledge 'customer' and from there it can specify the list of target knowledge it wishes to know about its customers. In the next phase of the methodology it will have to define how that target knowledge is going to be extracted. The extraction procedure will not have just data and information from customers as input, it will also utilise other sources of knowledge, such as employees in the organisation, the administration, and so forth. Therefore, in order to obtain the knowledge in a block, the block itself is not going to be the only element used as a source of knowledge, or the origin of that knowledge.

\section{PHASE III. Representation}

In the third phase of the methodology, after identifying and extracting the knowledge, the target knowledge will be represented in such a way as to provide us with a model of the knowledge map of the organisation (Lin \& Hsueh, 2006).

In line with the Model Driven Architecture (MDA) approach proposed by the Object Management Group (2003), in the KM-IRIS methodology the knowledge map is represented at different levels of abstraction. Initially, a model of the knowledge map is created at the CIM (Computation Independent Model) level, that is to say, independent of the computation. Later, transformation mechanisms are used to obtain the corresponding model at the PIM (Platform Independent Model) level. Modelling of the knowledge map, both at the CIM and the PIM level, is performed by means of the set of profiles developed for this purpose using the extension mechanisms provided by the latest version 2.0 of UML (Unified Modelling Language) (Object Management Group, 2004).

The CIM model of the knowledge map must include the conceptual blocks of knowledge that have been identified within the organisation, the target knowledge of each block, their location and the way they interrelate with the other elements on the map, as well as what input variables are required to obtain them, and the procedure for calculating or obtaining them. At this level, the CIM model is aided by the use of 
conceptual and ontological maps as a step prior to setting out a common framework of the concepts inherent to the organisation.

The PIM model will result from the transformation of the model of the CIM level knowledge map. This phase involves determining what part of the CIM model it is worthwhile computerising and then running the previously defined transformation mechanisms.

\section{PHASE IV. Processing}

Once the PIM model of the knowledge map has been obtained, the next step is to generate an executable model for it that can be run on a certain technological platform. This model, called a PSM (Platform Specific Model) in the MDA approach, is produced as the result of processing the knowledge map on a specific computer platform in order to allow the enterprise to obtain and utilise the knowledge wherever and whenever it is requested.

The activities to be carried out in this phase are similar to those proposed in any other object-oriented methodology for developing a computer system, but based on the previously obtained PIM models. The final result will be a knowledge portal that shows the knowledge map of the enterprise and offers different tools with which to locate and access it.

\section{PHASE V. Utilisation}

The last phase is the utilisation of the knowledge, which involves not only making a knowledge portal available to the organisation, but also providing it with the mechanisms it needs to make efficient use of the knowledge management system that has been developed (Desouza \& Awazu, 2005). This involves performing different types of tasks related to training, evaluation, continuous improvement and maintenance, some of the most notable of which include:

- Establishing policies and procedures to allow self-maintenance of the system (Tsai, 2003). In order to achieve this objective, the knowledge portal must be integrated with the different 
computer systems used in the enterprise. In this way all the explicit input variables will be extracted automatically. It is also important to introduce organisational changes so that tacit technical knowledge is codified and stored in such a way as to make it automatically available from the portal. For example, templates and forms must be defined for storing know-how, skills, experience and so forth, so that what was previously kept inside people's minds, in specific documents or was jotted down on a piece of paper is now integrated within the portal.

- Establishing a system of interrelated indicators that keep us permanently informed about the status of the knowledge management system, both at a strategic and a technological and organisational level. There are a number of different methods for measuring KM performance that can be used to achieve this goal and they can be classified into three types: qualitative and quantitative, financial and non-financial, and internal and external performance approaches (Liao, 2003). From a practical point of view, one of the most useful of these is the one proposed by Chen and Chen (2005), who developed a model that consists of a set of interrelated indicators to evaluate knowledge management activities from the following perspectives: knowledge creation, knowledge conversion, knowledge circulation, and knowledge execution.

- Consideration of cultural aspects to facilitate the participation and cooperation of all members of staff at the organisation, as well as all the stakeholders involved in the organisation's objectives, that is, interactions with customers, suppliers, administration, trade unions, and so forth.

\section{ADAPTATION OF THE GENERAL METHODOLOGY TO THE PARTICULAR CASE OF} AN ENTERPRISE

As far as the activities, tasks and results in each phase are concerned, the methodology described above can be applied to any type of organisation. Nevertheless, in order to make it easier to apply, specialised versions can be created by modifying the templates, questionnaires, reference models and so forth, to 
adapt them to the specific characteristics of each type of organisation. The adaptation of the general methodology to the specific case of enterprises can be seen below (see Figure 4). The methodology was applied to a large textile enterprise so as to be able to validate and refine it.

\section{PHASE I. Identification}

A set of blocks of knowledge that is sure to appear in any enterprise, and which the enterprise will need in order to identify its target knowledge, were defined for use when the organisation is an enterprise. These conceptual blocks are: owners, suppliers and customers, employees, administration and trade unions, organisation, product or service, process and resources. The target knowledge we seek to know was identified for each of these blocks and grouped in different ontological categories (Newman, 2000).

\section{PHASE II. Extraction}

The variables used to obtain the target knowledge that was previously identified, as well as the sources of tacit and explicit knowledge, were determined in this phase. The most notable explicit sources include databases, document databases, and business intelligence information systems, data warehousing, OLAP systems and data mining information systems. Tacit sources of knowledge are to found in the personnel that collaborate with the enterprise (customers, employees, suppliers, and so forth), as well as in organisations such as trade unions, business associations, and so forth. Lastly, the extraction and calculation procedures were defined for each item of target knowledge.

Table 1 shows an example of the results obtained in Phase I and Phase II of the KM-IRIS methodology after tailoring it for knowledge management in an enterprise. Employee and process deal with tacit sources of knowledge, and customer and product are concerned with explicit sources.

\section{PHASE III. Representation}

In order to facilitate the creation of the knowledge map for an enterprise, the KM-IRIS methodology includes a reference model that represents the target knowledge to be managed within a typical enterprise. 
Two aspects were taken into account during the development of this model. The first involved the use of ontologies (Holsapple \& Joshi, 2004) as a way of providing a common basis of understanding throughout the whole enterprise, while the second considered the utilisation of the MDA approach and UML to obtain a visual representation of the map of enterprise knowledge that can be turned into an executable model.

Thus, in building the reference model of the knowledge map a new business ontology was defined that took into account: (1) the different business concepts explained in Bertolazzi (2001); (2) the different conceptual blocks of knowledge proposed in phase I of the KM-IRIS methodology; and (3) the different dimensions defined within the context of the modelling of the business, so as to provide a holistic representation of the enterprise, i.e. business, organisation, process, product and resource.

This generic business ontology can also be tailored by any enterprise to fit its own domain according to the target knowledge it identifies.

The MDA approach proposed by the OMG (Object Management Group, 2003) was also used to develop a graphic model of the knowledge map at both the CIM and PIM levels, which in the fourth phase can be transformed into the corresponding PSM. UML was used as the modelling language in the creation of the models because it has become a commonly accepted standard for the object-oriented modelling of all kinds of systems. However, because UML is somewhat limited as a business modelling language, we took advantage of the new capabilities offered by UML 2.0 and used the profiles mechanism to extend the UML metamodel to the specific domain of enterprise knowledge. A profile was therefore defined in UML 2.0 that allowed the enterprise knowledge to be modelled in different views that took into account both the previously defined generic business model and the conceptual blocks of knowledge and target knowledge specified in earlier phases.

Figure 5 shows the conceptual diagram that was followed to elaborate the reference model of the map of enterprise knowledge at the CIM level, which represents the target knowledge that is to be managed in a typical enterprise and will later be used as a reference model in the development of the knowledge map of a particular enterprise. 
In Figure 5 it can be seen how the generic business ontology is taken as the starting point to establish the views needed to configure the map of enterprise knowledge in accordance with the conceptual blocks of knowledge and target knowledge that were identified at an earlier stage. Each of these views represents a specific conceptual block of knowledge that has been determined within the enterprise and it is linked to its corresponding ontological category. Thus, for example, the product view includes all the knowledge requirements set out in the earlier phases in terms of the products and services of the enterprise. Knowledge about these is represented as facts, rules and attitudes and is modelled according to the UML2 profile that was developed. In addition, the graphic model of each view offers access to different levels of detail and is connected to the other business views that are linked by means of the different ontological categories.

\section{PHASE IV. Processing}

In this phase, the PIM models obtained in the previous phase were taken as the basis to design an information system that enables an enterprise to process, store and present the map of enterprise knowledge in a suitable manner and depending on the user's access privileges, as well as to generate new knowledge (Sutton, 2005).

The computer system is organised around a knowledge portal, understood as being a computer solution that makes it possible to extract and process the information variables from the different sources of knowledge, and to generate and integrate the target knowledge required by the enterprise. Thus, the portal will enable us to gather knowledge generated about the different collaborations, projects/works under way, different activities, different ways of going about things, and the results that are gradually obtained, together with recommendations and both formal and non-formal best practices.

The corporate knowledge portal is built upon a technological infrastructure based on the intelligent integration of technological and functional components that allow a connection to be established among the following systems: 
- FrontSide: WebServices interfaces in each one of the applications designed for corporate management and for each of the conceptual blocks of knowledge, i.e. Customers/sales, Suppliers/purchases and the supply chain, Employees and Owners of the member enterprises (internal relationships), Administration, Trade Unions and Business District (collaborations/external actions).

- Business BackSide: financial, logistics, warehouses, accounting, human resources, and so forth.

- Knowledge Management BackSide.

Thus, using the Internet (together with other technologies for both presentation and the interface) as a means of interconnection, the knowledge portal will be the end point of the computer system supporting the knowledge management system within an enterprise (see Figure 6).

Consequently, when designing the knowledge portal, the following technologies must be integrated in a suitable and efficient manner:

- An Intranet that makes it possible to implement and integrate the different applications for internal knowledge management; it also allows users to obtain the target knowledge of the remaining conceptual blocks from internal sources within the enterprise.

- An Extranet for managing knowledge about both business (customers and suppliers) and the surrounding environment, that is to say, the administration, trade unions and the business district itself. It will also be used to extract part of the employees' and owners' target knowledge from these external sources so that it can be stored in the internal backside knowledge repository.

- An infrastructure consisting in networks and communications within the enterprise, in addition to the systems of control and management of access and authorisation that give rise to the different internal or external sub-portals, as well as endowing them with a suitable degree of security depending on the roles and user profiles that are defined.

- ERP (Enterprise Resource Planning), CRM (Customer Relationship Management) and SCM (Supply Chain Management) for managing business knowledge that will provide information that 
is useful for generating new knowledge on the Knowledge Management Intranet (Chalmeta, 2006).

- Workflow tools to control workflow and Groupware as a support for collaboration (Deek, 2003; Ellis, 1991).

- Data Warehousing, business intelligence and other decision support tools, which allow feedback and recommendations from the organisation's broad fundamental experience and from the knowledge stored in the backside knowledge repository to be incorporated into decision-making (Chalmeta \& Grangel, 2005).

- Other software applications, such as Document management systems, allow information fixed on some kind of support to be searched swiftly and according to different criteria, among other things. At the same time, they also make it possible to keep track of versions, control access by levels of security and, finally, avoid redundancy in the documents that are stored.

\section{PHASE V. Utilisation}

Although proper utilisation of knowledge management shares a number of common features regardless of the type of organisation in which it is applied (it is based on training, evaluation, continuous improvement and system maintenance), when the organisation is an enterprise the following specific aspects, among others, concerning the utilisation of knowledge management must also be taken into account:

- Cultural aspects to facilitate the participation and cooperation in the system of all the employees and owners, in addition to all the stakeholders involved in the organisation's business operations, the most important of which are its customers, suppliers, administration and trade unions.

- Consider training in this area as part of the strategic investment of the enterprise, like plants and equipment; it is thus ranked as a vital component in the construction of competitiveness.

- Guarantee the entire workforce the right to benefit both collectively and individually from the cognitive enrichment that arises from well-channelled and controlled transfers, and prevent any 
kind of monopolistic use of knowledge from being carried out by individuals who are driven by entirely personal, vested interests.

- Insist positively on interdepartmental interaction by making it possible for the departments in the enterprise to transfer their own explicit knowledge, so that by contrasting it they can also enrich it and complete it to the extent that the increase in efficiency and effectiveness of such transfers contributes to the resolution of management problems in each of the departments.

- Solve the problem of Property rights, by recognising the exclusive property rights of the knowledge held by the employee, according to the personal effort they make in carrying out their duties and the economic cost they had to pay, before they were taken on by the enterprise, in order to achieve the cognitive foundations that allowed them to later become part of it.

\section{A CASE EXAMPLE}

The KM-IRIS methodology was applied to a large textile enterprise. The procedure adopted for the application of the KM-IRIS methodology was as follows. First, a presentation was given at the enterprise so that management staff could see the aims of the knowledge management project. This was accompanied by an explanation of the KM-IRIS methodology, which was to be used to guide the execution of the project. During the presentation it was shown that the methodology has a staged structure and that it includes predefined extraction and calculation procedures, as well as clearly defined tasks and reference models of the target knowledge in a typical enterprise that would only need to be compared with the requirements of this company. These characteristics enabled the directors at the firm to quickly understand (1) the scope of the project; (2) the benefits that it was going to offer them; (3) the activities they would have to collaborate in; (4) the resources that would have to be assigned; and (5) the impact that the project would have on the enterprise. They were therefore already avoiding some of the main causes of failure when implementing KMS. 
The enterprise set up a committee that was responsible for decision-making in issues related to the project. This committee was made up of the information systems manager, the quality control manager, the logistics manager and the person in charge of communication and advertising. Other participants in the actual execution of the project included the managers from each department, members of staff from the computer department and, from time to time and as required, other members of the operating staff at the firm.

It is interesting to note that each of the members of the committee identified the benefits of the project according to his or her own background. For example, the information systems manager was the first to realise that the KMS was going to lead to the integration of the firm's computer systems. The enterprise had many corporate IT systems that were heterogeneous and not integrated with one another. Each of them was used to meet different needs in specific areas or aspects of the firm, such as ERP, CRM or SCM. Yet, these systems did not offer the organisation what it was looking for, that is to say, homogeneity, interoperability, easy access and knowledge of its possibilities throughout the different departments in order to prevent duplication of information or data, and so on. The decision to implement a new system centred on the knowledge portal, which was the entrance to all the knowledge in the organisation, was to be the factor that integrates the different technological solutions within the firm. On the other hand, the head of communications saw the portal as the ideal place to centralise all the useful knowledge the firm possessed regarding marketing, internal regulations, public news about the firm and its competitors, and so forth. At the same it could also be used to make such knowledge known among employees, customers, suppliers and other collaborators.

The project was actually carried out following the steps specified in the KM-IRIS methodology. First, the reference model was compared with the real situation of the textile enterprise so that the target knowledge they wished to manage could be defined. The most significant changes were the addition of a new conceptual block (the vision of the enterprise from outside) and incorporating, eliminating or renaming the predefined target knowledge. 
Once the target knowledge had been defined, the extraction and calculation procedure for each item of target knowledge was identified, together with the sources they could be obtained from. Explicit sources refer to the firm's IT system, which in this case consisted of the transactional computer system (ERP, CRM, specific logistics systems, etc.), the data warehouse, which provided reports and management control indicators, and the documentary information system. Tacit sources refer to persons and in order to extract their knowledge we drew up a number of surveys (for example, concerning the organisational climate and culture, employees' motivation and satisfaction, training needs), forms (for example, for actions carried out in response to a claim made by a customer; hence, from now on these are no longer contained in a person's experience, on a piece of paper or in an isolated document written out on the computer, but will instead be stored in a computer system), and collaborative tools.

All the results thus obtained were then recorded and used to generate a map of the knowledge of the enterprise. To do so, the methods of representation defined in the KM-IRIS methodology were used. The next stage was to start to develop the technological solution. This takes the form of a knowledge portal that can be accessed by the firm's collaborators. From a functional point of view, the portal is divided into five areas. One area allows access to the different blocks of knowledge the firm has. Another one is a search engine that allows us to find the target knowledge when we do not know the exact route. The search engine indexes not only the contents of this portal but also those from other external sources such as the corporate websites of customers, suppliers or competitors. A third area of the portal concerns collaborative environments, where members of staff from different departments can work on joint projects. The fourth area includes news related to the enterprise. Lastly, the fifth area is for administering the portal (definition of profiles, contents, services, configuration, etc.). From a technological point of view, the portal is connected to all the computer systems in the firm, so that it can extract the explicit input variables, and also to the forms, surveys and so forth, to enable it to extract the tacit input variables. Finally, implementation of the knowledge management system was carried out. The first step was to invite the top management staff at the firm to a presentation and to present the project publicly in the 
press (the enterprise thought that its having this sort of knowledge management system would enhance its image as an innovative firm). The next stage was to train users, who are currently running the system.

As well as improving the methodology as a result of applying it to different companies, the potential for developing research in this area has been proved and a series of lessons have been learned:

- In order for enterprises to integrate knowledge management effectively with all their existing business processes, both management and employees must understand and assimilate the strategic business value of knowledge management. These key participants must understand that knowledge management is not simply a technological strategy, but rather a business strategy that is essential for the success of their individual departments and of the organisation as a whole.

- The knowledge-oriented business model is seldom practised and poorly known, regardless of whether we are talking about an operational or management level.

- Limitations concerning the systemic vision of knowledge management. This behaviour is the result of historical factors that conditioned people and companies not to share knowledge.

- The need for more scientific production showing knowledge management methodologies and business experiences. As Blair (2002) says, experts learn from case studies.

- The need to encourage the training of staff in knowledge management. It has been shown that staff training programmes do not include the participation of employees in courses or other types of events related to knowledge management.

All these difficulties are related to the low level of awareness of the importance of knowledge management and, therefore, of the benefits that proper knowledge management can generate.

\section{CONCLUSIONS}


To successfully carry out a project aimed at developing and implementing a knowledge management system, it is essential to have a step-by-step methodology that directs the development and implementation processes. However, existing methodologies for developing information systems (ISDM) are not oriented towards the specific problems arising in this type of systems.

Within this framework, this paper has offered a description of a methodology obtained as the result of the KM-IRIS project. This methodology guides the process of developing and implementing a knowledge management system that allows knowledge to be collected, managed and applied, while ensuring the quality, security and authenticity of the knowledge provided. The methodology was first presented on a general level so that it could be used as a guide to manage knowledge in any kind of organisation that wished to do so, and it was then applied to a specific enterprise.

As a result, practitioners who follow this KM-based methodology for developing a KMS in an enterprise will benefit from a series of advantages that cannot be gained by using ISDM, including the following:

- A better definition of the vision and strategy of the project, because those in charge in the organisations in which the KMS is to be implemented will be in a better position to understand the scope and consequences of the project, as well as the important opportunities that can be obtained by having a knowledge management system.

- Better planning and management of the project, because the phases, tasks, techniques and documents to be used, as well as the results to be reached in each of the phases are all clearly defined.

- Greater chances of successfully implementing the project because the methodology has a reference model of the typical target knowledge of an enterprise and a specific modelling language for representing the knowledge map of a company in an intuitive, graphic manner. In this way the definition of the knowledge requirements will be easier and will better match the needs of the organisation. 
Finally, it is important to state the limitations of the study. The model was developed to be used in all kinds of organisations. However, in this study the applicability of the proposed methodology is tested by only one case - that of a large textile enterprise. Whether the proposed methodology can be applied successfully to other organisations that are different in terms of size, culture (e.g. national culture, organisational culture) and industry is still unknown. These heterogeneous characteristics may influence: 1) the identification of stakeholders such as customers, suppliers, government, academia, etc. and 2) the way knowledge is managed. As a result it may be necessary to add new blocks of knowledge, adapt the profile or perhaps modify or incorporate new phases, tasks or methods. Another aspect to be borne in mind is how the success of the KMS implementation can be evaluated by the KM-IRIS methodology. These questions will be on the future research agenda concerning the KM-IRIS methodology.

\section{Acknowledgements}

This work was funded by DPI2006-14708, CICYT DPI2003-02515 and the European Commission within the $6^{\text {th }}$ Framework Programme (INTEROP Network of Excellence, IST-2003-508011).

\section{References}

Abdullah, M.S., Benest, I., Evans, A., \& Kimble, C. (2002) Knowledge Modelling Techniques for Developing Knowledge Management Systems. In Proceedings of the 3rd European Conference on Knowledge Management (pp. 15 -25). Dublin.

Alavi, M., \& Leidner, D. E. (2001). Knowledge Management and Knowledge Management Systems: Conceptual Foundations and Research issues. Management Information Systems Quarterly, 25(1), 107-136.

Avison, D., \& Fitzgerald, G. (Ed.) (2006) Information Systems Development Methodologies, Techniques \& Tools, fourth edition, McGraw-Hill Education, Maidenhead. 
Bertolazzi, P., Krusich, C., \& Missikoff M. (2001). An Approach to the Definition of a Core Enterprise Ontology: CEO. In A. D'Atri, \& M. Missikoff, (Eds.), Proceedings of the International Workshop on Open Enterprise Solutions: Systems, Experiences, and Organizations (OES-SEO 2001) (pp. 14-15). Rome: Luiss Publications.

Blair, D.C. (2002). Knowledge management: Hype, hope, or help?. Journal of the American Society for Information Science and Technology, 53(12), 1019-1028.

Chalmeta, R. (2006). Methodology for customer relationship management. Journal of Systems and Software, 79(7), 1015-1024.

Chalmeta, R., \& Grangel, R. (2005). Performance measurement systems for virtual enterprise integration. Journal of Computer Integrated Manufacturing. 18, 73-84.

Chiu, C.-H., Hsu, M.-H., \& Wang, E.T.G. (2006). Understanding knowledge sharing in virtual communities: An integration of social capital and social cognitive theories. Decision Support Systems, 42(3), 1872-1888.

Chen, A., \& Chen, M. (2005). Measurement Practices for Knowledge Management: An Option Perspective. Lecture Notes of Computer Science, 3520, 387-399.

Day, R.E. (2001). Totality and representation: A history of knowledge management through European documentation, critical modernity, and post-Fordism. Journal of the American Society for Information Science and Technology, 52(9), 725-735.

Day, R.E. (2005). Clearing up implicit knowledge: Implications for Knowledge Management, information science, psychology, and social epistemology. Journal of the American Society for Information Science and Technology, 56(6), 630-635.

Deek F.P., \& McHugh J.A.M. (Ed.). (2003). Computer-Supported Collaboration with Applications to Software Development. Norwell: Kluwer Academic Publishers.

Desouza, K.C. and Awazu, Y. (2005). "Maintaining Knowledge Management Systems: A Strategic Imperative," Journal of the American Society for Information Science and Technology, 56(7), 765768. 
Devedzic, V. (1999). A survey of modern knowledge modeling techniques. Expert Systems with Applications, 17(4), 275-294.

Dretske, F.I. (Ed.). (1981). Knowledge and the Flow of Information. Cambridge, MA: MIT Press.

Eliasson, G. (2005). The nature of economic change and management in a new knowledge based information economy. Information Economics and Policy, 17(4), 428-456.

Ellis, C.A., Gibbs, S.J., \& Rein, G.L. (1991). Groupware: Some issues and experiences. Communications of the ACM, 34(1), 38-58.

Ernst \& Young Center for Business Innovation and Business Intelligence. (2001). An Executive Perspectives on Knowledge in the Organization. Working Paper.

Grangel, R., Chalmeta, R., \& Campos, C. (2006). Definition of Target Knowledge in Virtual Enterprises. In W. Abramowicz, \& H.C. Mayr (Eds.), Proceedings of the $9^{\text {th }}$ International Conference on Business Information Systems (BIS 2006) (pp. 256-266). Klagenfurt: Lecture Notes in Informatics.

Gray, P.H., \& Meister, D. B. (2006). Knowledge sourcing methods. Information \& Management, 43(2), 142-156.

Hall, H. (2003). Applying exchange theories in information science research. Library \& Information Science Research, 25(3), 287-306.

Heinrichs, J.H., \& Lim, J.-S. (2005). Model for organizational knowledge creation and strategic use of information. Journal of the American Society for Information Science and Technology, 56(6), 620629.

Holsapple, C.W., \& Joshi, K.D. (2004). A formal knowledge management ontology: Conduct, activities, resources, and influences. Journal of the American Society for Information Science and Technology, 55(7), 593-612.

Inmon, B. (Ed.). (1996). Building the data warehouse. New York: John Wiley \& Sons. Jayaratna, N., (1994). Understanding and Evaluating Methodologies, NISAD: A Systematic Framework, McGraw-Hill, Maidenhead 
Ke, W., \& Wei, K.K. (2005). Critical factors affecting the firm to share knowledge with trading

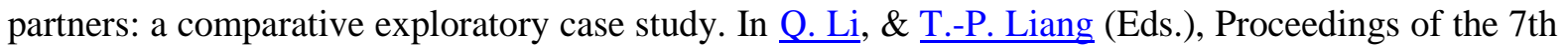
International Conference on Electronic Commerce (ICEC 2005) (pp. 177-183). Xi'an: ACM.

King, W.R., \& Marks, P.V.Jr., (2006) Motivating knowledge sharing through a knowledge management system, Omega, In Press, Corrected Proof, Available online 8 February 2006.

Liao, S. (2003). Knowledge management technologies and applications - literature review from 1995 to 2002. Expert Systems with Applications, 25(2), 155-164.

Lin, F., \& Hsueh, C. (2006). Knowledge map creation and maintenance for virtual communities of practice. Information Processing \& Management, 42(2), 551-568.

Lindvall, M., Rus, I., \& Sinha, S. (2003). Technology Support for Knowledge Management. Lecture Notes in Computer Science. 2640, 94-103.

McInerney, C., \& Day, R. (2002). Introduction to the JASIST special issue on Knowledge Management. Journal of the American Society for Information Science and Technology, 53(12), 1008-1009.

McInerney, (2002). Knowledge Management and the Dynamic Nature of Knowledge. Journal of the American Society for Information Science and Technology, 53(12), 1009-1019.

Meso, P., Madey, G., Troutt, M., Liegle, J., (2006). The knowledge management efficacy of matching information systems development methodologies with application characteristics—an experimental study. Journal of Systems and Software, 79(1), 15-28

Myers, P.S. (1996). Knowledge Management and Organizational Design: An Introduction. In P. S. Myers (Ed.) Knowledge Management and Organizational Design (pp 1-6). Boston: ButterworthHeinemann.

Newman, B.D., \& Conrad, K.W. (2000). A Framework for Characterizing Knowledge Management Methods, Practices, and Technologies. In U. Reimer (Ed.) Proceedings of the Third Int. Conf. on Practical Aspects of Knowledge Management (PAKM2000). Basel. 
Nonaka, I., \& Takeuchi, H. (Eds.). (1995). The Knowledge Creating Company: How Japanese Companies Create the Dynamics of Innovation. New York: Oxford University Press.

Object Management Group. (2003). MDA Guide Version 1.0.1, document number: omg/03-06-01 edition. Retrieved November 29,2006 from http://www.omg.org/cgi-bin/doc?omg/03-06-01

Object Management Group. (2004). Unified Modeling Language (UML) Specification: Superstructure, version 2.0., document: formal/05-07-04 edition. Retrieved November 29, 2006 from http://www.omg.org/technology/documents/formal/uml.htm

O’Leary, D.E., Kuokka, D., \& Plant, R. (1997). Artificial Intelligence and Virtual Organizations. Communications of the ACM, 40(1), 52-59.

O’Leary, D.E. (1998). Guest Editor's Introduction: Knowledge-Management Systems-Converting and Connecting. IEEE Intelligent Systems, 13(3), 30-33.

Revilla, E., Acosta, J., \& Sarkis, J. (2005). Value perceptions and performance of research joint ventures: An organizational learning perspective. The Journal of High Technology Management Research, 16(2), 157-172.

Schütt, P. (2003). The post-Nonaka Knowledge Management. Journal of Universal Computer Science, 9(6), 451-462.

Shin, M., Holden, T., \& Schmidt, R.A. (2001). From knowledge theory to management practice: towards an integrated approach. Information Processing \& Management, 37(2), 335-355.

Snowden, D. (2002). Complex acts of knowing: paradox and descriptive self-awareness. Journal of Knowledge Management, 6(2), 100-111.

Sutton, M. (2005). Review of "Integrated document and content management: Strategies for exploiting enterprise knowledge" by Len Asprey and Michael Middleton. Information Processing \& Management, 41(5), 1299-1301. 
Tsai, B. (2003). Information landscaping: information mapping, charting, querying and reporting techniques for total quality knowledge management. Information Processing \& Management, 39(4), 639-664.

Viswanathan M., Yang, Y. K., Whangbo, T. K., Kim, N. B., \& Garner B. (2005). Knowledge-Based Compliance Management Systems - Methodology and Implementation. Proceedings of the Fourth Annual ACIS International Conference on Computer and Information Science (ICIS’05).

Walters, S.A., Broady J.E., \& Hartley, R.J. ( 1994). A Review of Information Systems Development Methodologies. Library Management, 15(6) 5-19

Yadav, S, Shaw, N. Webb, L \& Sutcu, C. (2001). Comments on "Factors that Impact Implementing a System Development Methodology". IEEE Transactions on Software Engineering, 27(3) 279-281 


\begin{tabular}{|c|c|c|c|c|c|}
\hline $\mathbf{P}$ & $\begin{array}{l}\text { Conceptual } \\
\text { Block }\end{array}$ & EMPLOYEE & PROCESS & CUSTOMER & PRODUCT \\
\hline $\mathbf{A}$ & $\begin{array}{l}\text { Ontological } \\
\text { Category }\end{array}$ & Satisfaction & Sales & Profit & Cost \\
\hline $\mathbf{S}$ & $\begin{array}{l}\text { Target } \\
\text { Knowledge }\end{array}$ & $\begin{array}{l}\text { Economic } \\
\text { Satisfaction }\end{array}$ & Receive an order & $\begin{array}{l}\text { Economic } \\
\text { profitability } \\
\text { Customers }\end{array}$ & $\begin{array}{l}\text { Economic profitability } \\
\text { of Product }\end{array}$ \\
\hline I & \begin{tabular}{|l} 
Description \\
\end{tabular} & $\begin{array}{l}\text { Extent to which the } \\
\text { employee is } \\
\text { satisfied with the } \\
\text { salary he or she is } \\
\text { paid }\end{array}$ & $\begin{array}{l}\text { Best practices in } \\
\text { accepting orders }\end{array}$ & $\begin{array}{l}\text { Classification of } \\
\text { customers according } \\
\text { to their economic } \\
\text { profitability }\end{array}$ & $\begin{array}{l}\text { Classification of } \\
\text { customers according to } \\
\text { their economic } \\
\text { profitability }\end{array}$ \\
\hline I & $\begin{array}{l}\text { Input } \\
\text { Variables }\end{array}$ & $\begin{array}{l}\text { Opinion about } \\
\text { employees and } \\
\text { immediate } \\
\text { bosses } \\
\text { - Average salary } \\
\text { in the sector }\end{array}$ & $\begin{array}{l}\text { - Information } \\
\text { (Documents + Data) } \\
\text { that is needed or } \\
\text { generated to carry out } \\
\text { the task, and } \\
\text { identification of its } \\
\text { origin or destination } \\
\text { - Human and } \\
\text { technological } \\
\text { resources that are } \\
\text { involved } \\
\text { Controls or } \\
\text { associated regulations }\end{array}$ & $\begin{array}{l}\text { - } \begin{array}{c}\text { Annual sales } \\
\text { turnover }\end{array} \\
\text { - } \quad \text { Average price of } \\
\text { products acquired } \\
\text { - } \quad \text { Average quality } \\
\text { of products } \\
\text { acquired } \\
\text { - } \text { Number of } \\
\text { claims lodged } \\
\text { Average length } \\
\text { of payment period } \\
\text { in days } \\
\text { - Customer's } \\
\text { behaviour patterns }\end{array}$ & $\begin{array}{l}\text { - Average cost of the } \\
\text { raw materials and } \\
\text { labour used to } \\
\text { manufacture the } \\
\text { product } \\
\text { - Average profit } \\
\text { obtained from sale } \\
\text { of the product } \\
\text { Average cost } \\
\text { assigned to the } \\
\text { product as } \\
\text { advertising costs } \\
\text { Average cost } \\
\text { deriving from } \\
\text { financial expenses } \\
\text { arising from } \\
\text { marketing the } \\
\text { product }\end{array}$ \\
\hline & $\begin{array}{l}\text { Knowledge } \\
\text { Source }\end{array}$ & $\begin{array}{l}\text { Employee } \\
\text { Consultancy firms, } \\
\text { business } \\
\text { associations, trade } \\
\text { unions in the } \\
\text { business sector }\end{array}$ & Employee & $\begin{array}{l}\text { Databases and } \\
\text { document databases } \\
\text { Data Warehouses }\end{array}$ & $\begin{array}{l}\text { Databases and } \\
\text { document databases } \\
\text { Data Warehouses }\end{array}$ \\
\hline
\end{tabular}




\begin{tabular}{|l|l|l|l|l|l|}
\hline $\begin{array}{l}\text { Calculation } \\
\text { Procedure }\end{array}$ & $\begin{array}{l}\text { Statistical } \\
\text { calculation }\end{array}$ & $\begin{array}{l}\text { Detailed description of } \\
\text { the procedure for } \\
\text { running the task using } \\
\text { the IDEF0 modelling } \\
\text { language }\end{array}$ & Statistical calculation & Statistical calculation \\
\hline $\begin{array}{l}\text { Extraction } \\
\text { Procedure }\end{array}$ & $\begin{array}{l}\text { Questionnaires and } \\
\text { personal enquiries }\end{array}$ & $\begin{array}{l}\text { Templates for defining } \\
\text { profiles of work } \\
\text { positions drawn up by } \\
\text { the IRIS group }\end{array}$ & $\begin{array}{l}\text { ETL, OLT and OLAP } \\
\text { techniques } \\
\text { Data Mining } \\
\text { techniques }\end{array}$ & $\begin{array}{l}\text { ETL, OLT and OLAP } \\
\text { techniques } \\
\text { Data Mining techniques }\end{array}$ \\
\hline
\end{tabular}

Table 1. Example of Phases I and II of the KM-IRIS Methodology after tailoring it to the needs of an enterprise 